\section{WINGS PROJECT - REGIONAL EDUCATION CENTRE FOR SPECIALISED TRAINING AT AIRPORTS}

WINGS is a project for which Zagreb Airport Ltd. has applied as its Grant beneficiary and gained funds from the Instrument for Pre-accession Assistance (IPA IV).

On December 6t, 2013 at the Croatian Employment Service, the CEO of Zagreb Airport Ltd., Miroslav Drljača, PhD., signed a contract worth EUR175,761.97, out of which EUR134,048.07 come from EU funds.

The project was made by Zagreb Airport Ltd. as its Grant beneficiary, in collaboration with the partners: the Croatian Employment Service - Zagreb regional office, Zagreb International Airport Jsc. and the Faculty of Transport and Traffic Sciences, along with the Croatian Civil Aviation Agency as the project associate.

The aim of the Wings Project is to improve competences and competitiveness of the graduated unemployed traffic engineers. Through theoretical and practical lessons the participants improved their knowledge in the field of air traffic, along with their personal presentation skills, focusing on the increase of their competitiveness while job hunting on aviation labour market. The participants were trained by highly educated lecturers, instructors and mentors, who are also qualified experts with long-term experience in air transport and traffic.

The WINGS Project is conceptually divided into theoretical and practical classes, in a total duration of forty days. The theoretical classes of the course include lectures in specialized subjects related to airport (infrastructure, technique and technology, safety, security, economics and ecology) and so-called soft skills (communication and presentation skills). The theoretical part of the course is completed by HZZ specialists on a topic related to the possibility of self-employment.

The theoretical part is followed by twenty days of practical training in which participants are introduced to infrastructure, equipment and all processes at the airport. The practical part of the training is organized in a way that students are guided through the operational processes that employees perform on a daily basis at the Zagreb International Airport.

All the classes were drafted as the addition to the faculty syllabus and focused on the participants' easier integration into business processes, since all the participants obtain knowledge from the airport everyday work and develop personally in the form of "soft skills" programme. With a view of offering the combined knowledge of several segments, the guest lecturers from the Faculty of Transport and Traffic Sciences have included the scientific component in some of the classes, while the lecturers from the Croatian Employment Service contributed to the mere procedure of the employment process.

\section{Matija Bračić, Ph.D. Candidate Faculty of Transport and Traffic Sciences University of Zagreb}

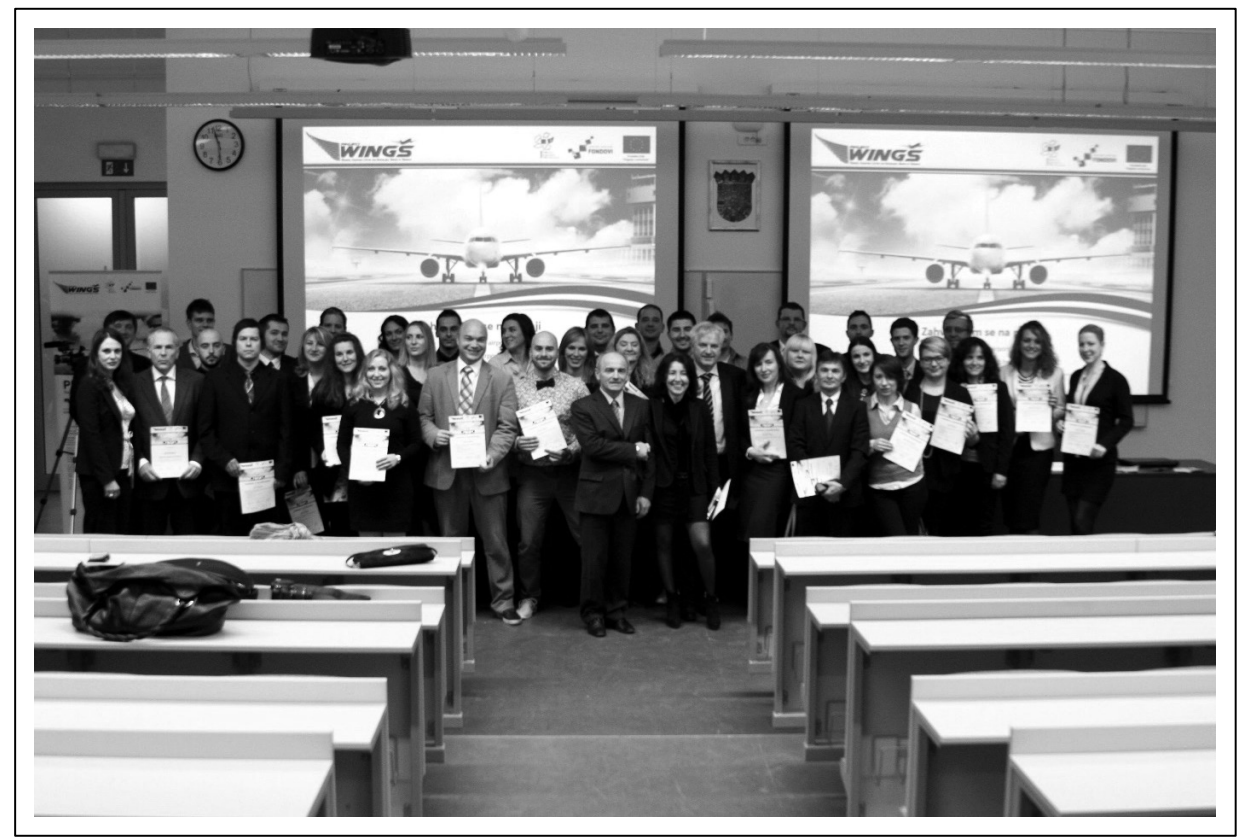

